\title{
ALFABETIZAÇÃO DE CRIANÇAS NEGRAS NA “TERRA DA LUZ”: A IMPLEMENTAÇÃO DA LEI 10.639/03 NO ESTADO DO CEARÁ
}

\author{
ARTIGO ORIGINAL \\ LIMA, Carlos Rochester Ferreira De ${ }^{1}$ \\ OLIVEIRA, Diana Nara Da Silva ${ }^{2}$ \\ LIMA, Francisco Alex Almeida ${ }^{3}$
}

LIMA, Carlos Rochester Ferreira De. OLIVEIRA, Diana Nara Da Silva. LIMA, Francisco Alex Almeida. Alfabetização de crianças negras na "Terra Da Luz": A implementação da lei $10.639 / 03$ no Estado do Ceará. Revista Científica Multidisciplinar Núcleo do Conhecimento. Ano 05, Ed. 05, Vol. 10, pp. 101-115. Maio de 2020. ISSN: 2448-0959, Link de acesso: https://www.nucleodoconhecimento.com.br/educacao/alfabetizacao-decriancas

${ }^{1}$ Doutorando em Educação Brasileira pela Universidade Federal do Ceará-UFC; Mestre em História e Culturas pela Universidade Estadual do Ceará-UECE; Especialista em Arte Educação e Cultura Popular pela Faculdade Darcy Ribeiro; Graduado em História pela Universidade Estadual do Ceará-UECE; Graduado em Pedagogia pela Faculdade Fael.

2 Doutoranda em Educação Brasileira pela Universidade Federal do Ceará-UFC; Mestre em Educação pela Universidade Estadual do Ceará-UECE; Graduada em História pela Universidade Estadual do Ceará-UECE; Graduada em Pedagogia pela Faculdade Fael.

${ }^{3}$ Graduando em Direito pela Universidade Federal do Ceará - UFC. 


\section{RESUMO}

Este estudo busca historicizar a situação da educação de crianças negras no Estado do Ceará, tendo como norte a implementação da Lei $n^{\circ}$ 10.639/2003. Procuramos construir um percurso, rápido, acerca da história da população negra, do final do século XIX até o início do XXI. A partir das ideias e representações, racistas, depreciativas e subalternizantes, que foram se cristalizando em torno dos afrocearenses, e estão, ainda, presentes nesse intervalo temporal no Brasil e no Ceará. Nossa análise é de caráter bibliográfico, e tem como objetivo (re)construir aspectos da realidade social cearense relativos à educação e as (im)possibilidades de alfabetização de crianças negras quanto ao desenvolvimento da autoestima e positividade étnica. Desse modo realizamos uma incursão a partir de um corpus teórico-epistemológico da História da Educação, História do Movimento Negro, Alfabetização Negra e Letramento Étnico. As questões que nortearam esta pesquisa foram: de que forma uma lei pode ter impactado na mudança de perspectiva qualitativa na educação afro-brasileira e afro-cearense? Qual o papel do Movimento Negro e das pautas como racismo, raça e multiculturalismo na efetivação da alfabetização étnica de crianças cearenses? Estas são algumas questões a serem refletidas.

Palavras-chave: Alfabetização de crianças negras, lei 10.639/2003, educação étnicoracial no Ceará.

\section{INTRODUÇÃO}

"Na nossa opinião se faz necessário muito mais para dar concretude a iniciativa do governo ao referendar a lei que trata da obrigatoriedade do ensino afro nas escolas brasileiras. Existem muitos obstáculos a serem ultrapassados para que a proposta se transforme em realidade."[4] O contexto educacional torna-se, por excelência, o espaço propício ao desenvolvimento de múltiplos olhares acerca da população afrodescendente do Estado do Ceará, primeiramente, porque há uma negligência nas discussões historiográficas e educacionais em relação à presença desta etnia em terras cearenses e, em segundo lugar, pela invisibilidade da participação nas lutas sociais deste povo. llário Sobrinho (2009), diz que há silenciamentos em relação a 
atuação de negras e negros no processo sistemático de conformação da territorialidade cearense. Este autor ressalta que boa parte do que é produzido em relação ao conhecimento da etnia negra em nosso país traduz os processos de formação e educação nacional e estaduais, que se pautam em formas de conhecimento que tem como base conceitual e referencial a Europa. Nesse sentido, desde o ingresso nas instituições escolares até a universidade, as crianças negras em processo de alfabetização e letramento social e os jovens negros se deparam com propostas educacionais que os invisibilizam. Há ainda uma hegemonia das visões, discursos e práticas eurocêntricas, mesmo que já possamos, ainda de forma esporádica, identificar modificações no trato teórico-metodológico, muito por causa da Lei $n^{\circ}$ 10.639/03.“E isto inclui, especificamente e principalmente, a formação educacional do Cearense. Portanto, não vejo como coincidência a falta de interesse em estudar e pesquisar as culturas afrodescendentes e africanas do Ceará." (SOBRINHO, 2009, p.67-68).

Essa sub-representação nas políticas públicas no Estado do Ceará e por seus agentes e órgãos, vai se redimensionando a partir de 2005, onde observaram-se os esforços para implementar a Lei $n^{\circ} 10639 / 03$. Nesse sentido, este momento é inaugural no que diz respeito as reflexões políticas, e no que tange as populações negras a nível estadual, levando-se em conta o contexto educacional e o saber histórico-acadêmico. Sendo assim, as questões raciais cearenses ganham novos olhares que paulatinamente serão refletidos nas retomadas dos processos didáticos-pedagógicos e na própria atualização das visões partilhadas pela sociedade em relação aos afrocearenses, sua História e Cultura.

As reflexões ora propostas, tem o objetivo de discutir as políticas públicas no Ceará para a implementação da Diretrizes Curriculares Nacionais para a Educação das Relações Étnico-raciais para a educação, e consequentemente a alfabetização de crianças negras cearenses a partir de desenvolvimento étnico e identitário. Teremos como eixo norteador as ações afirmativas internacionais e nacionais. Como metodologia tem-se a análise de documentos ligados à ONU, ao movimento negro e a Lei 10.639/03. Além de relatórios da Secretaria de Educação do Estado do Ceará 
(SEDUC_CE) acerca da implementação da referida Lei no processo de alfabetização de crianças negras em idade escolar, de onde sobressaltam os limites e as possibilidades de abordagem da temática afro no processo de alfabetização.

\section{A ALFABETIZAÇÃO E A IMPLEMENTAÇÃO DA LEI 10.639/03 NO ESTADO DO CEARÁ: AVANÇOS E RETROCESSOS}

O Estado do Ceará é o primeiro a abolir a escravidão, no dia 25 de março de 1884, por isso é também conhecido como "Terra da Luz". A partir desta alcunha, é necessário relativizar e refletir, do ponto de vista histórico, este fato e seus desdobramentos, tendo como parâmetro as relações escravagistas a nível nacional e internacional, para podermos identificar o contexto social e cultural onde criou-se e afirmou-se uma certa negação dos afrodescendentes no contexto social cearense. Destarte, não podemos naturalizar as lacunas das representações da etnia negra, seja nas práticas em educação ou nos manuais didáticos. Estes povos quando apareciam, ou era de forma secundária ou na perspectiva de seres inferiorizados, em condição sub-humanas e sem a menor condição de serem identificados como sujeitos históricos capazes de burlar o sistema estabelecido e lutar pela sua independência e direitos sociais.

Como uma tentativa de mudar este contexto são articuladas as Diretrizes Curriculares Nacionais para a educação das relações étnico-raciais e para o ensino da História e da Cultura afro-brasileira e africana. Este documento foi lançado no ano de 2004. O conjunto de Diretrizes traz orientações e recomendam que os currículos da Educação Básica, sejam revistos e sejam inseridos temáticas, assuntos e conteúdos que discutam e se aprofundem sobre raça, etnia, racismo e identidade negra. Do ponto de vista cronológico essas temáticas já eram pautadas pelos documentos oficias educacionais brasileiros, ou seja, nos Parâmetros Curriculares Nacionais (PCNs) de 1997, a Lei de Diretrizes e Bases da Educação (LDB) de 1996, já contemplam, mesmo que de forma incipiente, a diversidade étnica-brasileira. Tendo em vista estas iniciativas, que ocorreram na década de 1990, podemos identificar o início de reflexões teóricas, intelectuais e do próprio Movimento Negro, porém estes debates 
ficaram restritos ao mundo acadêmico, não conseguindo transformar-se em políticas públicas educacionais aplicáveis no cotidiano escolar.

Estas demandas teriam o intuito de atingir a todas as esferas educacionais, desde a Educação Infantil ( 3,4 e 5 anos de idade), pois é nesta etapa de formação que os conhecimentos relativos à identidade, combate ao preconceito institucional e o desenvolvimento de respeito e alteridade se desenvolvem. A pesquisadora Viviane Santos (2015) nos lembra que é na Educação Infantil e no ciclo de alfabetização, $1^{\circ}$, $2^{\circ} \mathrm{e} 3^{\circ}$ Ano do Fundamental I, que as crianças devem ter possibilidades de ter contado com práticas pedagógicas que desenvolvam os conhecimentos de si do mundo, o respeito a diversidade e de experiências que propiciem uma ampliação da tolerância e boa convivência com a coletividade nos diversos espaços, o que se torna muito relevante para o desenvolvimento da identidade infantil. Segundo Viviane Santos (2015):

O estudo e a prática pedagógica voltado para as relações étnico-raciais na Educação Infantil são recentes. Os debates em torno dessa questão vão ganhando visibilidade e as pesquisas que surgem voltadas para essa etapa, além de problematizar questões de discriminação na tenra idade, têm o objetivo maior de fortalecer, enraizar e tornar constante as práticas de respeito à diversidade racial. (SANTOS, 2015, p.26)

Em terras cearenses a movimentação para implementar a Lei no 10.639/03 só se inicia a partir de 2005, o que ocasionou discussões e reformulações do corpo das estruturas curriculares das escolas de Educação Básica, estaduais e municipais, na tentativa de efetivar esta política de ação afirmativa. As políticas que tratam de ações afirmativas se configuram como políticas de cunho social compensatórias, ou seja, são fomentadas a partir de mecanismos de intervenção do Estado. Podemos considerar também que estas são "importantes mecanismos sociais com características éticopedagógicas para os diferentes grupos vivenciarem o respeito às diversidades, sejam elas raciais, étnicas, culturais, de classe, de gênero ou de orientação sexual." (SILVÉRIO, 2007, p.21). 
Levando em consideração as reflexões da importância da efetivação da Lei no 10.639/03, assim como as estratégias formuladas como pautas de disputa dos diversos sujeitos que encamparam lutas por um projeto educacional que abarcasse a diversidade étnico-cearense é necessário reconhecer a correlação de forças de diversos grupos sociais na disputa por um projeto de Estado e de Sociedade, agora, preocupados com a garantia dos direitos sociais. Inquietações e dúvidas gestaram-se nos meios acadêmicos e escolares a partir da implementação da Lei ํㅜ 10.639/03 uma vez que as universidades não modificaram seus currículos, os professores chegavam nas escolas sem a sensibilização e o aparato teórico-conceitual adequado para lidar com o ensino das temáticas afro decentes, ou seja, a lei existia, porém a sua efetivação tornara-se difícil, em virtude da ausência de conhecimento teórico, inexistência de formações continuadas e pelo fato dos materiais didáticos ainda serem carregados de preconceitos, ou mesmo a inexistência destes.

"Como ensinar o que não se conhece? Para além das interrogações, a lei revelou algo que os especialistas em História da África vêm alertando há um certo tempo: 'esquecemos' de estudar o continente africano". (OLIVA, 2003, p.5). As ausências e lacunas diante dos conhecimentos referentes à história e à cultura da África fazem com que sejam reproduzidos preconceitos e visões que subalternizam os povos daquele continente e consequentemente desenvolvam nas práticas sociais e pedagógicas representações maniqueístas das negras e negros na história do Brasil e, particularmente, do Ceará, mesmo sendo este Estado o primeiro a abolir a escravidão no país.

Em outra perspectiva devemos destacar que historiografia brasileira tem nos últimos anos se interessado pelas relações que o Brasil estabelece com a África desde o século XVI. Essas relações históricas ganham espaço nas discussões políticas e históricas, no entanto ainda de forma "acanhada", não ocorrendo um aprofundamento e uma sistematização que possa subsidiar uma prática pedagógica no "chão da escola" eficiente e eficaz no combate ao racismo e ao preconceito dispensado em relação às populações negras. Para se ter uma ideia, ainda hoje, causa muita confusão as formas de implementação da Lei oㅜ 10.639/03, professores de Português, 
Artes, História, Geografia não tem consciência de como abordar estas questões de forma efetiva. No que diz respeito aos professores da Educação Infantil e os docentes do Ensino Fundamental I, relatam que é muito complexo trabalhar essas temáticas com os alunos em período de alfabetização e letramento. Isso demonstra as fragilidades do processo de implementação das relações étnico-raciais no ambiente escolar.

Este panorama, até aqui exposto, pode ser sintoma e desdobramento da ausência de discussões sobre as relações das populações negras brasileiras, ou reflexos da inexistência de sensibilização diante das putas afro-brasileiras que só fará parte dos debates políticos de forma efetiva na década de 1990. Desse modo "a chamada questão racial só entrou na agenda de debates das políticas públicas na metade dos anos 90." (NASCIMENTO, 2007, p.66). No entanto, os requerimentos para que as "pautas negras" fizessem parte do debate político em âmbito nacional, já se fazia presente na mobilização da sociedade, o que ficou gravado no texto da Lei na nossa Carta Constitucional de 1988, chamada de "Constituição Cidadã"; nesse momento havia um movimento que reivindicava junto ao Estado brasileiro medidas eficazes e políticas que descentralizassem o acesso à educação, luta por salários melhores, inserção de pessoas com deficiências, mulheres e outras minorias sociais historicamente excluídas.

Ao nos reportarmos para o Ceará podemos destacar que os discursos e as representações sobre a presença de negros nesse estado foram se gestando a partir da materialização de ideias que negaram a presença significativa de negras e negros nesta região. Isto se deu porque a historiografia cearense tradicional levou em consideração, por muito tempo, somente as questões econômicas que estavam ligadas na configuração do processo colonizador, e também por conta do Ceará ter se desenvolvido, sido colonizado, tardiamente, no século XVII, o que diferenciava as formas de trabalho dos negros escravizados cearenses de outras regiões. A escravidão no Ceará teria, segundo uma historiografia tradicional, sido mais amena por conta da utilização dos escravizados na lida com o gado, em regime extensivo. Ora, o que faz de um sujeito escravo não é somente a forma de trabalho, mas a 
coisificação, a objetificação, a perda dos direitos civis e a possibilidade de mercantilização dos negros pelo "seu dono", que poderiam vende-los como uma mercadoria qualquer. Consequência disto é que foi-se engendrando subrepresentações dos negros cearenses, não sendo possível, durante muitas décadas, ir de encontro a estes discursos no ambiente escolar. E, principalmente, na Educação Infantil e no ciclo de alfabetização, $1^{\circ}, 2^{\circ}$ e $3^{\circ}$ anos do Ensino Fundamental I, que são etapas de suma importância para o desenvolvimento de atitudes antirracistas, e práticas que desenvolvam as relações de ensino e aprendizagem que combatam todas as formas de preconceitos. A esse respeito Frank Ribard (2008) nos ajuda a refletir:

(...)A problemática do negro no Ceará, articula-se com a série de imagens que compõe e justificam o discurso oficial da ausência ou do caráter muito marginal da presença do negro no Estado. Nesta versão, sustentada pela historiografia clássica produzida no âmbito do Instituto Histórico e Geográfico Brasileiro (IHGB), A Escravidão numa terra dominada pela economia pecuarista, teria sido incipiente, relativamente branda e precocemente desmantelada (1884) pelo pioneirismo do movimento abolicionista, por estas razões a participação negra teria sido tão pouco representativa a referência ao negro no Ceará desparecendo inclusive no período republicano, como se fosse o próprio negro que tivesse sido abolido em vez da escravidão. (RIBARD, 2008, p.209).

Para refletirmos sobre o processo de escolarização e alfabetização de meninas e meninos negros no estado do Ceará é necessário averiguar as entrelinhas, os entraves e os silêncios, que do ponto de vista histórico cerceou, por exemplo, a autoestima e o orgulho em ser negro, uma vez que as imagens construídas sobre esta população, para além da ideia da incipiência de negros, criou-se a ideia de uma "Terra da Luz", ou seja, a partir do processo de abolição da escravidão o Estado tornara-se branco, alvo, iluminado. A historiadora Silva Maria Vieira ao refletir sobre a presença dos afro-cearenses na atualidade, realiza algumas reflexões sobre a identidade e o pertencimento negro, tendo como referência o censo do Instituto Brasileiro de 
Geografia e Estatísticas (IBGE) realizado em 2010. Esta pesquisadora nos chama atenção para o fato de que neste levantamento, levando em consideração o total da população do estado, somente $4,64 \%$ se assume como preta, na contramão disto $61,6 \%$ dizem ser pardos. Ela lembra, que nas pesquisas anteriores o percentual de pretos era muito inferior à do ano de 2010 , o que demonstra que de algum modo as ações educacionais, as mudanças de representação através da mídia e as políticas reparatórias estão dando frutos. Como lembra a pesquisadora: "Mas é certo que a cada novo censo a população preta aumenta e isso não é fruto de um milagre ou de um boom da população negra. Isso se dá principalmente porque mais pessoas estão assumindo sua história e sua afro descendência. " (VIEIRA, 2012, p.1/2).

Tais reflexões, apontam para uma mudança na identidade e na positividade e autovalorização das representações dos negros deste estado. Isto é um processo gradual e lento, porém consegue fugir dos padrões alimentados por séculos que se instauraram a partir da desqualificação dos afro-cearenses e, consequentemente, para a presença do racismo nos diversos contextos e no cotidiano da nossa população, seja "nos castigos, nas piadas e nos provérbios, ou nas experiências de vida dos negros cearenses, muitas vezes obrigados a se negar enquanto negros". (RIBARD, 2008, p.210).

Ao procurar delimitar o termo "ação afirmativa", temos que nos apropriarmos, minimamente, sobre suas transformações históricas, desde seu nascimento nos Estados Unidos até o seu aparecimento no Brasil com toda uma carga conceitual e argumentativa de teóricos, juristas e acadêmicos. No Brasil, somente nas últimas décadas do século XX é que as discussões no entorno da efetivação das políticas de ações afirmativas entram em pauta. O Movimento Social Negro é quem vai capitanear, neste primeiro momento, essas reflexões iniciais, paulatinamente, houve um processo de ampliação em outros espaços, como é o caso do jornal impresso, da TV e do rádio. Em relação aos espaços governamentais estas discussões desenvolvem-se no final da década de 1980 e início dos anos de 1990. Como demonstra Siss (2003), ao falar que "no âmbito das organizações que integram o Movimento Negro Nacional os resultados das discussões sobre este tema apontam para uma ausência de consenso 
sobre a validade e a necessidade da implementação de tais políticas entre nós". (SISS, 2003, p.31). Nesse sentido, há uma polifonia de pensamentos e discursos entre os intelectuais, estudiosos e militantes do Movimento Negro, onde algumas parcelas destes grupos levantaram argumentos contraditórios à aplicação de políticas públicas afirmativas no país. Como é o caso de "dirigentes de organizações do Movimento Negro, que afirmam que criar uma Secretária especial para os afro-brasileiros, separada das outras a isola e, assim, as outras secretárias ficam desobrigadas de enfrentar o debate." (CONTINS E SANT'ANNA, 1996, p.36).

No âmbito governamental, Federal, Estadual e Municipal - algumas discussões e iniciativas em relação às políticas de reparação social e étnica insurgem-se em meados da década de 1990. Em 1996 ocorreu o Seminário Internacional "Multiculturalismo e Racismo: O Papel da Ação Afirmativa nos Estados Democráticos Contemporâneos", este foi promovido pelo Ministério da Justiça, deste evento nasceu o GTI (Grupo de Trabalho Interministerial), este coletivo tinha por finalidade realizar discussões e desenvolver a elaboração e implementação de projetos na esfera política que garantissem a valorização e a mudança positiva dos padrões de vida das negras e negros brasileiros.

Partindo dos altos índices de desigualdades dentro da população brasileira, em especial os grupos de pessoas negras, que são marginalizados em diversas esferas, o GTI teve um papel importante ao articular as demandas relacionadas às políticas afirmativas a nível nacional. Para o Grupo Interministerial as ações não poderiam ocorrer de forma isoladas, mas teriam que ter a articulação de diversos setores da sociedade, como o Movimento Negro, os Partidos Políticos, igrejas, universidades, sindicatos e a iniciativa privada. Um consenso do GTI foi o de que a área da Educação seria de suma importância para a efetivação das políticas afirmativas no Brasil.

Pela documentação e as informações apresentadas até este momento podemos perceber que houve "grande desejo" dos organismos internacionais para dar prosseguimento à implementação de políticas afirmativas que atingissem aos setores discriminados, do ponto de vista histórico e geográfico e em relação as questões do âmbito racial da sociedade brasileira. Estas ações partiram de preocupações de 
entidades internacionais como o Banco Mundial. Este se articulou pautado em um discurso que visava "aliviar a pobreza", e foi seguido por outros organismos de caráter multilateral como a UNESCO e a ONU. A partir da conjuntura da organização econômica no mundo estes organismos buscavam estabelecer estas políticas de cunho compensatório, que se destinava a grupos que nem sempre eram minorias, como é o caso da população afro-brasileira, esta representa mais de $60 \%$ da população, tendo a Educação como "carro chefe", mais especificamente a História e a Cultura das populações negras segregadas.

\section{MULTICULTURALISMO, RAÇA E RACISMO NO PROCESSO DE ALFABETIZAÇÃO DE CRIANÇAS CEARENSES}

"Europeus dizem: bom, se os outros, árabes e negros querem preservar sua identidade, temos o direito de preservar a nossa também, nós não somos obrigados a viver junto com eles." (MUNANGA, 2000, p.28). Não podemos compreender o multiculturalismo de maneira análoga, uma vez que este vocábulo apresenta muitas semânticas acompanhadas de dimensões diferenciadas. E isto por si só possibilita leituras sobre diferentes perspectivas, dependendo do modelo social onde o multiculturalismo se apresenta, além é claro dos elementos constitutivos do contexto ao qual este está inserido. $\mathrm{Na}$ abordagem do conceito de multiculturalismo precisamos levar em consideração que este precisa ser identificado a partir dos verdadeiros "problemas" relacionados a cultura e também como elemento constitutivo de onde sobressaem as estratégias no campo político que tem o intuito de desenvolver as demandas sociais do ponto de vista integrado. Os elementos chaves para o entendimento das relações multiculturais são assim os valores partilhados nacionalmente e os elementos que incorporam os diversos grupos sociais. Para Gonçalves e Silva (1998), o multiculturalismo foi se constituindo como uma marca das sociedades onde apresentavam-se elementos culturais em estratificação, ou seja, separados. A diversidade, nesses modelos, é vista como elemento que impede a construção da unidade das nações. Sendo assim, nesses tipos de sociedade haverá parcelas sociais que ficarão excluídas dos processos de tomadas de decisão. 
Maria Nilza da Silva e Pires Laranjeira (2007) ao problematizar as questões raciais no Brasil comentam que no decorrer do século XIX a sociedade brasileira converteu-se em um "laboratório" para estudiosos e cientistas do mundo todo que abordavam temáticas relacionadas à raça. Estes autores relatam-nos que a mestiçagem, a mistura de raças, era o fator comum que inquietava os cientistas estrangeiros. Havia nessa época uma construção discursiva que afirmava ser prejudicial o contato entre as diferentes raças[5], segundo esse pensamento deveria haver a preservação de uma suposta raça superior, a ariana, em detrimento de uma orientação de eliminar gradualmente as raças que não se enquadrassem nesse modelo pré-estabelecido. "A ciência justificou e norteou o comportamento racista difundindo ideias como a necessidade de proteção contra o contágio das raças consideradas inferiores. " (SILVA E LARANJEIRA, 2007, p.125).

Esses aspectos ligados as más representações afro-brasileiras e afro-cearenses ficaram impregnados nas práticas sociais e nos ambientes formativos escolares. Essas ausências de ações efetivas por parte dos professores desde os primeiros anos de escolarização são frutos de escolhas curriculares que se distanciaram das histórias e das culturas afro-cearenses e pelo esvaziamento das temáticas negras nas formações, iniciais e continuadas. "Falar, vivenciar e experimentar sobre a questão da diversidade do nosso país para aprendermos a respeitar é um imperativo ético, respeito devido a essa grande parcela da população brasileira. " (SANTOS, 2015, p.42). Como bem lembra a pesquisadora étnico-educacional Vivianne dos Santos, onde ressalta a relevância da formação dos docentes para a compreensão de aspectos que tem impacto direto na vida das crianças, seja porque precisam desenvolver sua identidade e sua cultura, ou pelo seu modo de ser e de viver. "Salientamos ainda que não se faz necessário haver a presença de um afro descente em sala para que possamos pensar em incluir em nossa proposta pedagógica, no fazer cotidiano de nossas instituições de educação o trabalho com essa temática. " (SANTOS, 2015, p.42).

llário Sobrinho (2009) nos relembra que o período após a abolição da escravatura cearense é caracterizado por um ufanismo e exaltação do movimento abolicionista no 
Estado e uma sub-representação da etnia negra, beirando a vitimização dos afrocearenses. Nesse sentido o negro aparece na memória cearense a partir de um discurso onde nega-se a presença deste elemento social e também quando, a partir da historiografia oficial do Ceará, a História e a Cultura negra são controladas pelo imaginário ligada aos discursos da elite cearense. Nesse sentido, "a última década do século XIX vê a acentuação do processo institucional de repressão contra as manifestações culturais negras fortalezenses que, no imaginário da elite remetiam ao tempo da escravidão e que, associadas ao atraso da barbárie. " (SOBRINHO, 2009, p.98).

"Os professores precisariam abordar a participação do povo negro na construção do país, na construção da riqueza nacional, na acumulação do capital e também as suas batalhas, rebeliões, quilombos e suas lutas mais contemporâneas."[6] Ao realizarmos um apanhado das produções históricas a nível nacional e em contraponto a história local cearense, identificamos que um processo de reformulação das representações sociais negras através de construções ideológicas que subsidiaram narrativas da subalternização da população negra em harmonia com os pressupostos científicos do século XIX, que usaram como ditame para as suas supostas certezas, as diferenças biológicas e o conceito determinista de raça. Estas ideias alimentaram durante muito tempo a produção intelectual, a formação acadêmica e as práticas pedagógicas nas escolas de Educação Básica, sendo replicadas em manuais didáticos e nas metodologias usadas desde o processo de alfabetização das crianças cearenses. "Em geral, a história dada segue o livro didático e ele é insuficiente para dar conta de uma forma mais ampla e crítica de toda a história." [7]

Nesse sentido podemos imaginar que meninas e meninos afro-cearenses, em seus bancos escolares, não puderam durante décadas desenvolver uma identidade e autoestima positiva, pois estavam rodeadas, no ambiente escolar, de parâmetros que pregavam a superioridade da etnia branca, além da justificação dos processos de dominação da população negra, como foi o caso da escravidão brasileira e cearense. Esses parâmetros, interligados com os discursos da historiografia tradicional cearense em relação ao processo de libertação dos negros nesse estado, alimentaram a ideia 
do vitimismo que estava incorporado aos afro-cearenses. Neste ponto Frank Ribard assevera que "a versão contada da 'Terra da Luz', terra autoproclamada branca, no máximo cabocla, onde o negro, diretamente associado ao escravo, só aparece como vítima redimida pela mão magnânima e humanista dos heróis abolicionistas cearenses. " (RIBARD, 2008, p. 210).

A explanação destas mentalidades nos ajuda a visualizar as agruras que uma criança negra passava, e ainda passa de certo modo, no ambiente escolar, seja pela ausência de uma educação que as inserisse no mundo letrado de forma a desenvolver sua autoestima e referenciais positivos de sua história e memória, ou pelas ausências de uma alfabetização e letramento que leve em consideração as demandas e especificidades étnicas dos discentes. "Uma outra dificuldade é a questão da formação dos nossos professores nesta área. Não podemos abordar bem aquilo que não conhecemos bem. E esta é uma limitação que precisa ser superada urgentemente. Na pauta do dia: capacitação nesta área para todos os professores[8]".

Mesmo com a implementação da Lei № 10.639/03, que no Ceará se dá de forma tardia, a História e a Cultura afro-cearense ainda não conseguiu ser estudada e problematizada de forma coerente nos diversos estabelecimentos de ensino, quer sejam escolas públicas ou particulares. Isto é resquício da inexistência de formação inicial e continuada que consiga abarcar a complexidade de outras leituras que destoem das narrativas e representações que foram se construindo a partir do século XIX e se reatualizaram através de metamorfoses constantes, conseguindo, assim, chegar até nós não só nas conversas informais, do senso comum, mas nos materiais escolares impressos e nas formas de didatização metodológicas dos aspectos culturais e históricos dos afro-cearenses. Assim, as mudanças de perspectiva ainda não atingiram o "chão da escola", e estas têm seu grau de negligência aumentados se levarmos em consideração o processo de alfabetização e letramento das meninas e meninos negros cearenses. 


\section{CONSIDERAÇÕES FINAIS}

Pelo que conseguimos identificar na presente pesquisa é notório que ainda há um abismo entre a efetivação das políticas públicas compensatórias através da implementação da Lei n 10.639/03 e o processo de alfabetização formal, que respeite a diversidade étnica, as matrizes culturais afro-cearenses, a autoestima e a identidade das crianças negras. Percebemos ao estudarmos os documentos estatais, nos pesquisadores estudados e nos fragmentos dos textos que contemplam as narrativas dos relatórios da SEDUC-CE, que se faz necessário preencher as lacunas seculares que se pautaram na desvalorização e subalternidade da história e da cultura das populações negras no Ceará.

Nessa perspectiva as leituras aqui problematizadas acerca dos processos sociológicos, e histórico-educacionais nos permitem identificar o conceito de racismo associado à escravidão, isso a nível de Brasil. No Ceará não há muita diferença, pois no decorrer do processo abolicionista deste Estado podemos identificar que as teses que discorriam sobre as diferenças raciais a superioridade da raça branca e a inferioridade negra, do ponto de vista biológico, foram os elementos que embasaram e deram norte aos líderes abolicionistas no Ceará.

Nesse ínterim, o ambiente escolar, no que diz respeito ao processo de alfabetização e letramento, está focado em uma proposta pedagógica que visa até o final do $3^{\circ}$ ano do Ensino Fundamental I desenvolver competências e habilidades que proporcionem o desenvolvimento linguístico-matemático, em oposição, aos conteúdos ligados as ciências humanas, como os conceitos históricos e geográficos que contribuam com outros olhares e práticas étnico-raciais, por exemplo. Nesta esfera há uma grande carência do domínio teórico-conceitual e metodológico dos docentes para o trato com a temática afro-cearense.

A classe professoral ainda planeja e desenvolve suas atividades com despreparado quando o assunto são as relações étnicas. Nesse sentido as alunas e os alunos deixam de ter acesso aos conteúdos e conceitos que contribuam com a valorização histórica, estética e identitária destes sujeitos em formação. Faz-se urgente que sejam 
revistas as formações iniciais e continuadas de professores no intuito de ressignificar os conhecimentos ultrapassados, os discursos, ditados e as falas preconceituosas sobre os afro-cearenses, e que os alunos da Educação Básica, principalmente àquelas que estão em processo de alfabetização e letramento, possam ser oportunizados a outras leituras e representações das populações negras, no passado e na atualidade. Um excelente começo seria a mudança curricular, nas universidades e nas escolas, que incluísse os elementos da História e da Cultura negra cearenses, além, é claro, a efetiva formação de professores mais acuidosa com as temáticas relacionadas ao mundo africano, afro-brasileiro e afro-cearense.

\section{REFERÊNCIAS}

CONTINS, M; SANT'ANNA, L. C. O movimento negro e a questão da ação afirmativa. In: Estudos feministas. IFCS/ UFRJ - PPCIS/UERJ, 1996, vol.4, n¹.

FARIA, Denilda Caetano de. 0 acesso e a permanência dos estudantes de origem popular à Educação Superior: uma avaliação do Programa Conexões de Saberes na UFT, Campus de Palmas, 2011.

GONÇALVES, L.A.O.; SILVA, P. P. B.G. O jogo das diferenças: O multiculturalismo e seus contextos. Belo Horizonte: Ed. Autentica. 1998.

JACCOUD, L. "Racismo e República: o debate sobre o branqueamento e a discriminação racial no Brasil". In: THEODORO, Mário. (org.). As políticas públicas e a desigualdade racial no Brasil 121 anos após a abolição. Brasília: IPEA, 2008.

LARANJEIRA, Pires e SILVA, Maria Nilza da. Do problema da "raça" às políticas de ação afirmativa. In. PACHECO, Jairo Queiroz e SILVA, Maria Nilza da Silva. (Orgs). O negro na Universidade: Direito a inclusão. Brasília, DF: Fundação Cultural Palmares, 2007.

MUNANGA, K. O Racismo no mundo contemporâneo. In: OLIVEIRA, I. de. Org. Relações raciais: Discussões contemporâneas. Niterói: Intertexto, 2000. 
NASCIMENTO, E.L. Introdução à História da África. In: UNB. Centro de Educação à Distância. Educação Africanidades Brasil.Brasília:UnB/CEAD, 2007.

OLIVA, Anderson ribeiro. A História da África nos bancos escolares. Representações e imprecisões na literatura didática. Estudos Afro-Asiáticos. Salvador, nำ, 2003.

PACHECO, Jairo Queiroz e SILVA, Maria Nilza da Silva. (Orgs). O negro na Universidade: Direito a inclusão. Brasília, DF: Fundação Cultural Palmares, 2007.

REIS, C. R.; SOUSA, C. A. Breve análise sobre a ação afirmativa. Disponível em: <http://jus2.uol.com.br/doutrina/texto.asp?id=6050 > Acesso em: 10/11/ 2012.

RIBARD, Franck. África, mãe negra do Brasil ou apontamentos para uma nova consciência multicultural. In: Em Tempo: História, Memória, Educação./ Kênia Sousa Rios e João Ernani Furtado Filho (orgs.). Fortaleza: Imprensa Universitária, 2008.

SANTOS, Vivianne Alves dos. CONCEPÇÕES DAS PROFESSORAS SOBRE O TRABALHO COM AS RELAÇÕES ÉTNICO-RACIAIS NA EDUCAÇÃO INFANTIL. Trabalho de Conclusão de curso apresentado ao Curso de Especialização em Educação Infantil da Faculdade de Educação da Universidade Federal do Ceará, Fortaleza,2015.

SILVÉRIO, Valter Roberto. A ação afirmativa: Uma politica pública que faz a diferença. In: O negro na Universidade: o direito a inclusão. Brasília: Fundação Cultural Palmares, 2007.

SISS, Ahyas. Afro-brasileiros, cotas e ação afirmativa: Razões históricas. Quartet. Rio de Janeiro. Niterói: PENESB, 2003.

SOBRINHO, José Hilário Ferreira. Cultura popular e as culturas afrodescendentes. In. Negros no Ceará: História, Memória e Etnicidade. (Orgs.) Cristina Rodrigues Holanda. Fortaleza, Museu do Ceará, 2009. 
VIEIRA

Silva

Maria.

Negros

no

Ceará.

http://cenpah.wordpress.com/2012/07/30/negros-no-ceara/. Acessado em 20/02/2019 as $12: 00 \mathrm{H}$.

\section{APÊNDICE - REFERÊNCIAS DE NOTA DE RODAPÉ}

4. Relatório das Escolas de Ensino Fundamental, enviados à SEDUC - CE, 2010

5. $\mathrm{Na}$ atualidade o conceito de raça não é mais utilizado, haja vista que nenhum embasamento científico o sustenta, hoje trabalhamos com o conceito de etnia.

6. Relatório das Escolas de Ensino Fundamental, enviados à SEDUC - CE, 2015.

7. Relatório das Escolas de Ensino Fundamental, enviados à SEDUC - CE, 2008.

8. Relatório das Escolas de Ensino Fundamental, enviados à SEDUC - CE, 2007.

Enviado: Maio, 2020.

Aprovado: Maio, 2020. 